\title{
Uma Improvável Queimadura: Relato de um Caso de Esclerose Sistémica Difusa
}

\author{
An Unlikely Burn: A Case Report of Diffuse Systemic Sclerosis \\ Catarina Dias Rosa*, Ana Adão**, Mariana Bastos ${ }^{* * *}$, Sandra Almeida*, Filipe Prazeres*
}

\section{Resumo}

Introdução: A Esclerose Sistémica Difusa (ESD) é uma doença autoimune, de causa desconhecida, que pode afetar múltiplos sistemas orgânicos, condicionando gravemente a qualidade de vida dos doentes afetados. Embora não sejam conhecidos os eventuais agentes que modifiquem a evolução da doença, a terapêutica imunossupressora deverá ser iniciada numa fase precoce, sendo por esse motivo primordial o reconhecimento desta patologia nas fases mais iniciais. Inevitavelmente a ESD condiciona elevado impacto a nível físico e psicológico do doente, devendo ser considerados fatores como o estado nutricional, a dor, o descondicionamento físico, a atrofia muscular, as comorbilidades, o impacto psicológico da doença e o isolamento social. A abordagem dos doentes com ESD deve ser por isso baseada numa visão global e multidisciplinar.

Descrição do caso: Apresenta-se um caso de uma muIher de 50 anos, sem antecedentes pessoais ou familiares de relevo para a doença atual. Queixas de edema e rubor de ambas as mãos associado a rigidez matinal de 30 minutos com duas semanas de evolução. Ao exame objetivo verificava-se edema em todos os dedos de ambas as mãos, rubor ligeiro nas articulações metacarpofalângicas, interfalângicas distais e interfalângicas proximais. Não se verificava dor à palpação ou mobilização das articulações e ligeira limitação na flexão. Foi orientada a nível hospitalar, inicialmente pela especialidade de Medicina Interna, tendo sido colocada a hipótese diagnóstica de ESD após realização de meios

\begin{abstract}
Background: Diffuse Systemic Sclerosis (DSS) is an autoimmune disease of unknown cause that can affect multiple organ and systems, with a serious impact on patients' quality of life. Although agents that modify the course of the disease are not known, immunosuppressive therapy should be started at an early stage, and its early recognition is therefore of great importance. The DSS inevitably causes a high physical and psychological impact on the patient, and factors such as nutritional status, pain, physical deconditioning, muscle atrophy, comorbidities, psychological impact of the disease and social isolation should be considered. The approach of patients with ESD should be based on a global and multidisciplinary approach.
\end{abstract}

Case Description: We present a case of a 50-year-old woman with no personal or family history of relevance to the current disease. The patient presented edema and flushing of both hands associated with morning stiffness of 30 minutes with two weeks of evolution. The objective examination showed edema in all the fingers of both hands, slight redness in the metacarpophalangeal, proximal and distal interphalangeal joints, absence of pain at palpation or mobilization of the joints, and slight limitation in flexion. She was initially hospital-oriented by the specialty of Internal Medicine and the diagnostic hypothesis of SSD was placed after completing diagnostic tests. Since it is a multiorganic disease, it is currently undergoing consultations in Rheumatology, Dermatology, Physical and Rehabilitation medicine and Pneumology.

\footnotetext{
USF Beira Ria, ACeS Baixo Vouga, ARS Centro

*** USF Flor de Sal, ACeS Baixo Vouga, ARS Centro

*** USF Vale do Cértima, ACeS Baixo Vouga, ARS Centro
} 
complementares de diagnóstico. Por se tratar de uma doença multiorgânica, mantém seguimento atualmente em consultas de Reumatologia, Dermatologia, Pneumologia e Medicina Física e de Reabilitação.

Comentário: Embora a ESD seja uma doença extremamente rara, o relato deste caso realça a importância do conhecimento por parte do médico de família dos sinais de alarme desta doença reumatológica. Além disso, tem ainda um papel relevante na gestão da multimorbilidade associada e no suporte aos cuidadores do doente.

Palavras-Chave: Esclerose, Esclerodermia, Abordagem

\section{Introdução}

A Esclerose Sistémica Difusa (ESD) é uma doença multissistémica, de natureza autoimune, caracterizada por inflamação e hiperreatividade micro e macrovascular ${ }^{1,3}$. Caracteriza-se por alterações a nível vasomotor e fibrose, com consequente atrofia da pele, tecido subcutâneo, músculos e órgãos internos (gastrointestinal, pulmões, coração, rins e sistema nervoso central), sendo acompanhada de alterações a nível imunológico ${ }^{2}$. A sua etiologia mantem-se desconhecida ${ }^{1}$, sendo mais frequente em mulheres com idades compreendidas entre os 35 e os 55 anos $^{1,3}$. O envolvimento renal e pulmonar são as principais causas de morte na ESD ${ }^{1,2}$. Embora não sejam conhecidos agentes que modifiquem a evolução da doença ${ }^{1}$, a terapêutica imunossupressora deverá ser iniciada numa fase precoce5, com vista a melhorar a qualidade de vida, minimizando a lesão orgânica. Os tratamentos imunossupressores têm demonstrado alguma eficácia apenas em fases precoces da doença ${ }^{1}$. Tratando-se de uma doença que pode progredir rapidamente para a morte, o reconhecimento precoce da ESD é fundamental, sendo a referenciação para consulta especializada uma prioridade. A abordagem destes deve ser sempre baseada numa visão global e multidisciplinar ${ }^{3}$. Inevitavelmente a ESD condiciona elevado impacto tanto a nível físico como psicológico do doente, interferindo na vida familiar e social. Devem ser considerados fatores como o estado nutricional, a dor, o descondicionamento físico, a atrofia muscular, as comorbilidades, o impacto psicológico da doença, a autoimagem e o isolamento social ${ }^{1}$.
Commentary: Although ESD is an extremely rare disease, this case report highlights the importance of the family physician's knowledge of the warning signs of rheumatic diseases. In addition, the family doctor also has a role in managing the associated multimorbidity and support of the patient's caregivers.

\section{Keywords:}

\section{Descrição do Caso}

Mulher, 50 anos de idade, caucasiana, operária numa fábrica de conservas de peixe. Pertence a uma família reconstituída, habitando com o seu companheiro e um filho de anterior casamento, Graffar classe média, APGAR familiar altamente funcional. Tem como antecedentes pessoais hipertensão, dislipidemia e depressão major. Medicada com olmesartan medoxomilo $10 \mathrm{mg} /$ dia, atorvastatina $10 \mathrm{mg} /$ dia e fl oxetina $20 \mathrm{mg} /$ dia. Nega alergias conhecidas, nega hábitos tabágicos, alcoólicos ou consumo de drogas de abuso. O Plano Nacional de Vacinação encontrava-se atualizado.

Em janeiro de 2015 iniciou edema e rubor de ambas as mãos, associado a rigidez matinal de 30 minutos, uma semana após ter manuseado peixe congelado. A doente recorreu à sua unidade de saúde no dia 27 de janeiro, duas semanas após o início do quadro, pensando tratar-se de uma queimadura pelo frio. Ao exame objetivo apresentava edema em todos os dedos de ambas as mãos, rubor ligeiro nas articulações metacarpofalângicas (MCF), interfalângicas distais (IFD) e interfalângicas proximais (IFP), ausência de dor à palpação ou mobilização das articulações e ligeira limitação na flexão. Foi programada consulta de reavaliação após duas semanas e pedidas analises sanguíneas que demonstraram VS $18 \mathrm{~mm}$ e PCR $1.10 \mathrm{~mm} / \mathrm{dL}$. Pelo resultado das análises e pela persistência das queixas, foi solicitada consulta de Medicina Interna no centro hospitalar de referência, a qual se realizou a 19 de fevereiro. 
Ao exame objetivo apresentava esclerodactilia, tom violáceo em todos os dedos de ambas as mãos, assim como artrite nas articulações IFP. Foram pedidas análises sanguíneas que viriam a revelar LDH 245 U/L, PCR 0.50mm/DI, ANAs 1/640 - Padrão Mosqueado e Anticorpos Anti-Scl70 311.00 - Positivo. Na consulta subsequente, dia 18 de março, pela suspeita de ESD, foram solicitados vários exames complementares de diagnóstico e pedida consulta de Reumatologia com carácter de urgência.

Na consulta de Reumatologia, realizada a 21 de maio, manifestava queixas de mialgias inespecíficas, parestesias difusas envolvendo os dedos e palmas das mãos, tumefação difusa dos dedos, associadas a queixas compatíveis com fenómeno de Raynaud de dupla fase, artralgias de ritmo misto envolvendo os dedos com rigidez matinal $>1 \mathrm{~h}$, alopécia exuberante, dispneia para médios esforços, disfagia, xerostomia. Ao exame objetivo sobressaíam crepitações inspiratórias finas na auscultação pulmonar de ambas as bases, esclerodactilia com eritrodermia e Raynaud moderado (sem úlceras ou lesões cicatriciais), esclerodermia facial, bem como da zona do decote (Figura 1), antebraços e pernas bilateral, associado a telangiectasias plantares. 0 exame de imagem torácico revelou discretas áreas de densificação de baixa densidade do tipo "vidro despolido" no lobo médio, língula e lobos inferiores, indiciando patologia intersticial, além de discretas bronquiectasias nos segmentos superiores dos lobos inferiores, áreas de densificação irregulares e reticulação nos segmentos posteriores dos lobos inferiores sugestivas de fibrose (Figura 2). o estudo funcional ventilatório revelou diminuição moderada da capacidade de difusão alvéolo-capilar pelo monóxido de carbono. A manometria esofágica revelou mais de 50\% das deglutições ineficazes. $\mathrm{Na}$ capilaroscopia verificaram-se alterações compatíveis com esclerose sistémica.

Figura 1. Esclerodermia zona do decote

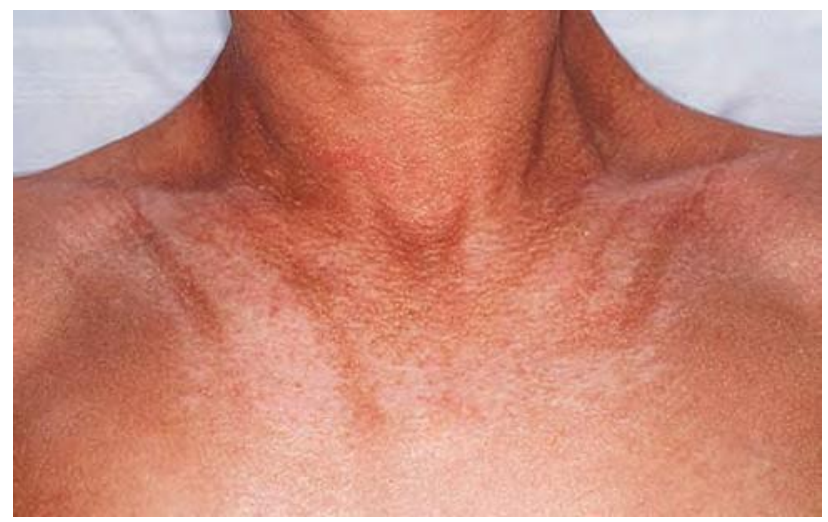

Figura 2. TC torax

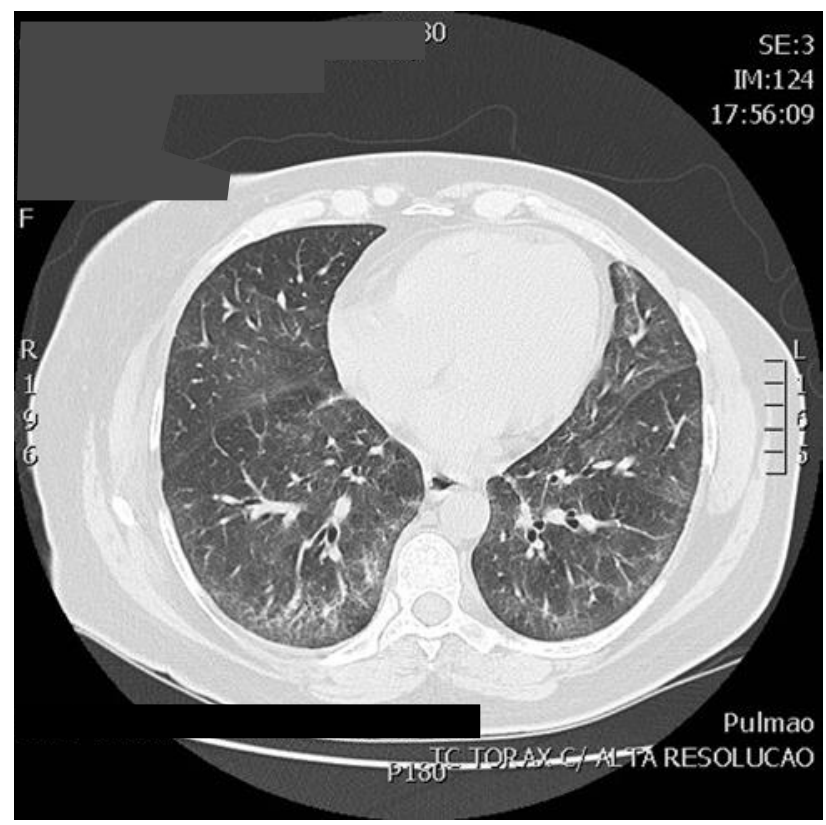

Face ao quadro clínico e resultados dos exames complementares de diagnóstico foi colocado o diagnóstico de ESD com atingimento imunológico, pulmonar, gastroesofágico, articular e dermatológico. Foi iniciado tratamento farmacológico com ciclofosfamida $750 \mathrm{mg} / \mathrm{m} 2$ em pulso mensal, prednisolona $7,5 \mathrm{mg}$ id, clotrimazol 960mg em dias alternados, metoclopramida 10mg id, carbonato de cálcio $1500 \mathrm{mg}$ + colecalciferol $400 \mathrm{UI}$ id, ácido alendrónico 70mg + colecalciferol 2800 Ul semanal, pantoprazol 40mg id. Neste momento mantém seguimento em consultas hospitalares de Reumatologia, Dermatologia, Pneumologia e Medicina Física e de Reabilitação.

\section{Comentário}

A evolução dos factos narrados retrata a importância do conhecimento precoce dos sinais de alarme da doença reumatológica por parte do MF. Foi fundamental a realização cuidada do exame objetivo e colheita de história da doença atual, mesmo quando a utente já atribuía uma causa à sintomatologia apresentada. Destaca-se ainda neste caso a celeridade com que a doente foi orientada nos cuidados de saúde secundários, tendo tido consulta de Medicina Interna em menos de um mês após o início da sintomatologia. Além disso, é ainda de sublinhar a importância da articulação entre as diversas especialidades hospitalares e os cuidados de saúde primários. 


\section{Referências Bibliográficas}

1. Coelho PC, Cunha I, Cruz M, Salvador MJ, Santos MJ. Manual Prático da Esclerose Sistémica GDRESIS. Sociedade Portuguesa de Reumatologia.

2. Schwartz RA. Systemic Sclerosis. Medscape [Internet]; 2016 [cited 2016 Set 2]. Available from: http://emedicine. medscape.com/article/1066280-overview

3. Cordeiro A. Esclerose Sistémica. Boletim Informativo da Sociedade Portuguesa de Reumatologia. 2011. Sociedade Portuguesa de Reumatologia. 265378/07

4. Cordeiro A. Systemic Sclerosis: know more, hope more. Acta Reumatol Port. 2016 Jan-Mar;41(1):6-7.

5. Denton CP, Hughes M, Gak N, Vila J, Buch MH, Chakravarty K, Fligelstone K, Gompels LL, Griffiths B, Herrick AL, Pang J, Parker L, Redmond A, Van Laar J, Warburton L, Ong VH. BSR and BHPR guideline for the treatment of systemic sclerosis. Rheumatology (Oxford). 2016 Jun 9. pii: kew224.

\section{Conflito de Interesses}

As autoras declaram não ter conflito de interesses.

\section{Endereço para Correspondência}

Catarina Dias Rosa: catarina.dias.rosa@gmail.com 